\title{
Visual Processing of Motion-defined Form: Selective Failure in Patients with Parietotemporal Lesions
}

\author{
D. Regan, ${ }^{1,2}$ D. Giaschi, ${ }^{1, a}$ J. A. Sharpe, ${ }^{1,2}$ and X. H. Hong ${ }^{3}$ \\ 'Department of Ophthalmology, and ${ }^{2}$ Neuro-Ophthalmology Unit, Division of Neurology, The Toronto Hospital, \\ University of Toronto, Toronto, Canada M5T 2S8, and 'Department of Psychology, York University, \\ North York, Ontario, Canada M3J 1P3
}

The following psychophysical data were obtained from 13 patients with unilateral cerebral hemispheric lesions and 20 control subjects: speed thresholds for detecting and for recognizing motion-defined letters, speed thresholds for detecting coherent motion and for discriminating its direction, and visual acuity for recognizing letters of $96 \%$ and $11 \%$ contrast. Acuity was between $6 / 6$ and 6/3 for all patients. Four patients showed a selective loss of ability to recognize motion-defined letters, while the ability to detect those same letters was spared, as was the ability to detect coherent motion and discriminate its direction (type I loss). Three patients showed a loss of ability both to recognize and to detect motion-defined letters, while the ability to detect coherent motion and discriminate its direction was spared (type II loss). All seven patients who failed to recognize motiondefined letters had extensive lesions in parietotemporal white matter underlying Brodmann cortical areas 18, 19, 37, 39, 21 , and 22. The lesion was in the left hemisphere for three patients and in the right hemisphere for the remaining four. The region of overlap in these seven patients was not invaded by the lesion in any of the other slx patients, and none of these six patients showed a loss of ability to recognize motion-defined letters. Three patients showed selective loss of acuity for low-contrast letters with normal Snellen acuity. The lesions in these three patients extended more posteriorly than in any other patient, and their region of overlap was in white matter underlying areas 18 and 19.

We conclude that (1) the loss of ability to recognize letters in seven patients was specific to motion-defined letters rather than being a general loss of letter-recognition ability, (2) this visual loss was specific to motion-defined form rather than being a general failure of motion processing, and (3) the visual loss was not produced by lesions that did not involve the localized cerebral region specified above.

\footnotetext{
Received Nov. 4, 1991; revised Dec. 27, 1991; accepted Jan. 9, 1992.

We thank the patients who kindly agreed to take part in this study. We are grateful to Dr. Mark Bernstein, Division of Neurosurgery, The Toronto Hospital for allowing us to study his patients and to Mrs. P. Cheng for technical assistance We thank J. H. R. Maunsell for comments on an earlier version of the manuscript D.G. was supported by a Natural Science and Engineering Research (NSERC) fellowship. X.H.H. was supported by NSERC Grant OGP0002024 to D.R. This research was supported by National Eye Institute Grant EY07569 to D.R. and by Medical Research Council of Canada Grants MT-9332 to D.R. and MT-5404 to J.A.S. and sponsored by the U.S. Air Force Office of Scientific Research.

Correspondence should be addressed to D. Regan, Room 375, Behavioral Sciences Building, York University, 4700 Keele Street, North York, Ontario, M3J 1P3, Canada.

a Present address: Department of Ophthalmology, University of British Columbia, Vancouver, Canada V5Z 1 S6.
}

Copyright $(\mathcal{C}) 1992$ Society for Neuroscience $0270-6474 / 92 / 122198-13 \$ 05.00 / 0$
To explain the existence of type I and of type II loss with sparing of the detection and discrimination of coherent motion, we propose that motion information is processed hierarchically. We further suggest that homologs of the socalled motion and color/form pathways (i.e., areas V1/MT/ MST/7a and areas $\mathrm{V} 1 / \mathrm{V} 4 / \mathrm{IT}$ ) are interconnected to form a distributed system that is important for the recognition of motion-defined form. We attribute type I and type II loss to damage to this system, including damage to the interconnections between the cortical pathways just listed and possibly also to disruptions of connections between visual cortical areas and subcortical nuclei.

It is self-evident that, unless an object's retinal image differs visually from its surroundings, the object cannot be seen and therefore cannot be recognized visually. It has long been known that any one of several visual differences can render an object visible and enable it to be recognized. These differences include a difference in luminance (i.e., luminance contrast, as in the case of a dim letter on a bright background or a sinewave luminance grating), a difference in velocity [i.e., motion parallax (von Helmholtz, 1866)], a difference in color, a difference in texture, and a difference in binocular disparity. Most research on the detection and discrimination of spatial form has been restricted to the special case of contrast-defined (CD) form.

The literature on the detection and discrimination of spatial form defined by velocity contrast, chromatic contrast, texture contrast, and disparity contrast is comparatively sparse (reviewed in Bergen, 1991; Morgan, 1991; Regan, 1991b; Tyler, 1991; Wilson, 1991). In a series of previous articles, we have reported that the best values of several spatial discriminations can be similar for motion-defined (MD) shapes and for comparable CD shapes. In particular, the best values of shape discrimination (Regan and Beverley, 1984; Regan and Hamstra, 1991a), vernier acuity (Regan, 1986), and orientation discrimination (Regan, 1989a) are similar at low to moderate dot densities. A parsimonious hypothesis (Regan, 1989a) is that the early stages of processing of motion and contrast are parallel, that both motion and contrast are processed hicrarchically, and that visual responses to $\mathrm{MD}$ and $\mathrm{CD}$ form converge onto the stages at which the spatial discriminations are determined. For example, orientation discrimination threshold might be determined by an orientation-opponent stage (Regan and Beverley, 1985) that is common to $\mathrm{MD}$ and $\mathrm{CD}$ form. We thank an anonymous referee for pointing out that this is a special case of the more general idea, discussed by many authors, of multiple visual cues converging in higher-level processing (Regan and 
Beverley, 1979; Regan, 1982; De Yoe and Van Essen, 1988; Switkes et al., 1988; Albright and Chaudhuri, 1989; Cavanagh et al., 1990).

This hypothesis can account for the results of two recent clinical studies. Of 25 patients with multiple sclerosis and/or optic neuritis, seven had elevated speed thresholds for reading large $(6 / 60)$ MD dotted letters yet had normal contrast thresholds for reading the same dotted letters when they were luminance defined rather than motion defined (Kothe et al., 1990; Regan et al., 1991). These seven patients also had normal visual acuity for solid low-contrast letters and normal Snellen acuity. We concluded that (1) the failure in letter recognition was specific to MD letters rather than being a general failure of letter recognition or word blindness [i.e., alexia (Brain and Walton, 1969)] or a language defect, and (2) the neural mechanism that underlies shape discrimination for MD form is in some degree physiologically different from the neural mechanism that underlies shape discrimination for CD form. In a further study on 10 patients with multiple sclerosis, six patients had elevated speed thresholds for recognizing MD letters while speed thresholds for detecting those same letters were spared, as were speed thresholds for discriminating leftward from rightward coherent motion, speed thresholds for detecting the presence of coherent motion, contrast thresholds for recognizing CD dotted letters, low-contrast acuity for solid letters, and Snellen acuity. One patient had elevated speed thresholds for both recognizing and detecting MD letters, while all the other thresholds just mentioned were spared. We concluded that, in some patients, the failure to recognize MD letters was not due to a general failure of the neural processing of motion information (Giaschi et al., 1991, 1992).

Multiple sclerosis is associated with the presence of multiple, widely distributed plaques in white matter, so we are left with the following questions: (1) whether only multiple distributed lesions can cause the selective failure to recognize MD letters, or whether this selective dysfunction can be caused by a single discrete lesion and, if so, (2) whether this lesion must have some unique cercbral location and extent. This study addresses these questions by investigating visual loss in patients with unilateral cerebral hemispheric lesions.

\section{Materials and Methods}

\section{Stimulus}

(1) Motion-defined letters. A random pattern of bright dots of near$100 \%$ contrast was displayed on a CRT monitor using a technique developed from a previously described method (Regan and Hong, 1990). The pattern was presented on a high-resolution Sony multiscan monitor (model CPD1304) and generated by an IBM PC clone with a $33 \mathrm{MHz}$ processor and a VGA Wonder graphics card that gave a resolution of 1024 (horizontal) $\times 768$ pixels at a frame rate of $60 \mathrm{~Hz}$. The width of the display was $23.5 \mathrm{~cm}$, so that at the viewing distance of $6 \mathrm{~m}$ the display subtended $2.2^{\circ}$, and each pixel subtended $0.13^{\prime}$ arc. Dot density was $25 \%$. There were 60 jumps/sec at the faster dot speeds, but the jump rate fell below $60 \mathrm{~Hz}$ at the slowest dot speeds. We carefully confirmed that dot motion appeared to be smooth and continuous at the slowest dot speed used in this study.

The dot pattern contained a camouflaged letter that could not be detected when the dots were either all stationary or all moving in the same direction at the same speed. Figure $1 A$ illustrates the effectiveness with which the letter was camouflaged when all dots were stationary. The letter was made visible by moving the dots within the letter rightward at $V$ degrees/sec while moving the dots outside the letter leftward at $V$ degrees/sec, so that relative velocity was $2 V$ degrees/sec. The dots were switched on at the instant that they started moving, Note that the letter itself was stationary. Figure $1 B$ illustrates that, although the letter was clearly visible to the eye, the letter was almost invisible in a pho- tograph. This was because the human visual pathway is sensitive to the direction of motion, but a camera is not. Figure $1 D-G$ illustrates the reason why, in this study, as in previous studies (Regan, 1986), we chose to move dots within the camouflaged form at the same speed as dots outside the camouflaged form, but in the opposite direction. To aid explanation, the dot density in Figure $1 D-G$ was $2 \%$ rather than the $25 \%$ used in the experiment. Figure $1 E$ confirms that, just as in Figure $1 B$, the letter, though visible to the eye, was almost invisible to a camera when dots inside and outside the letter moved at equal and opposite speeds. However, when dots outside the letter moved at a different speed to dots inside the letter (Fig. $1 F$ ) the letter was not only visible to the eye, but was also evident in a photograph. Again, when dots inside and outside the letter moved in different directions, the letter was evident in a photograph (Fig. 1G). Because a camera is not sensitive to the direction of motion, the letters in Figure $1 D-G$ could not have been rendered visible by differences in the direction of dot motion. Clearly, they were rendered visible by texture contrast. Therefore, if a form is rendered visible to the eye hy a difference in either speed or the direction of motion, we cannot necessarily assume that the visibility is created entirely or even partly by the neural processing of motion information. In principle, the letter could be seen and recognized by a subject who was totally blind to motion per se. For example, temporal integration in cortical neurons that were sensitive to the length and orientation of a line might cause them to respond to a moving dot as though the moving dot were a line of some specific length and orientation-much as the camera responded in Figure $1 D-G$.

We should add that careful inspection of the $2 \%$ dot density in Figure $1 E$ reveals the camouflaged letter and (with a little imagination) one might also read the letter in the Figure $1 B$ photograph of the stimulus we used in this study. This is logically unavoidable, because dots are created and destroyed along the nonhorizontal boundaries of the concealed letter. Therefore, trajectories that are shorter than average occur near the letter's boundaries. This weak cue to the shape of the letter can be masked by creating a new random dot pattern many times per second, and we have shown that spatial discriminations are little degraded by the maneuver (Regan, 1986; Regan and Hamstra, 1991a) so that, in practice, the accretion and deletion of texture at the letter's boundaries make little contribution to visibility. ${ }^{1}$

The test procedure was as follows. A trial consisted of two presentations, each of 1 sec duration, separated by an interval of duration 0.5 sec. A motion-defined letter was displayed during one trial, and during the other trial all dots moved leftward. Dot speed was the same during both trials. Ten different letters were used. All letters were of $50^{\prime}$ arc subtense; that is, they were the same angular size as letters on the $6 / 60$ line of a Snellen chart. Dot speed was held constant during any given block of 10 trials. All 10 letters were presented in random order during any given block of 10 trials. A tone signaled the onset of each trial. Dots were switched off between presentations. Subjects were instructed to name the letter presented, to indicate whether the letter was in the first or second presentation (two-alternative forced choice), and to guess if unsure. The first block of 10 trials was at the fastest dot speed of 0.45 degrees/sec. The next block of 10 trials was at the next slower dot speed, and so on. Measurements were continued until the subject's response accuracy deteriorated to chance level. Speed threshold for recognizing MD letters was defined as the dot speed for $75 \%$ correct reading score obtained by plotting the percentage of correct responses versus dot speed. Speed threshold for detecting MD letters was defined as the dot speed for judging at $75 \%$ correct level whether the letter was in the first or the second presentation of a trial. Speed thresholds were estimated from the psychometric functions obtained by plotting the percent correct responses versus dot speed.

(2) Discrimination of leftward from rightward motion. The same dot pattern display was used as for the MD letters except that all the dots on the screen moved in the same direction (i.e., moved coherently). As for stimulus 1 above, a criterion-free method was used (two-alternative forced choice). A trial consisted of one $1 \mathrm{sec}$ presentation during which dots moved leftward or rightward at some fixed speed. Subjects were instructed to state whether the motion was leftward or rightward and to guess if uncertain. Ten trials were presented with the same dot speed, five leftward and five rightward in random order, and the subject's

${ }^{1}$ Software to generate MD letters is available gratis to researchers. Send a blank 5.25 or 3.5 inch disk in a returnable cardboard disk envelope addressed to author D.R. The software will run only on an IBM PC-type 386 or true clone with a VGA Wonder Plus graphics card. 

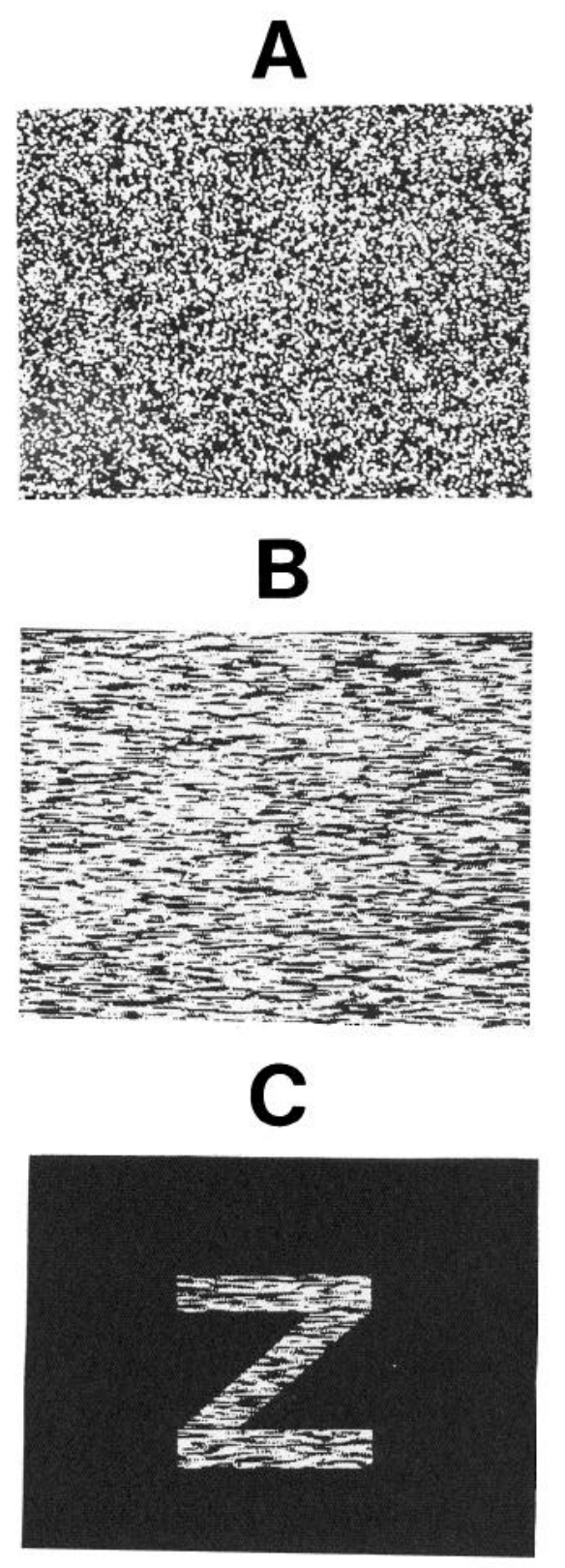

Figure 1. A, A letter was perfectly camouflaged within this pattern of dots. Dot density was $25 \%$. $B$, Dots within the letter moved rightward at speed $V$ while dots outside the letter moved leftward at the same speed $V$. This motion rendered the letter visible to the eye, but as illustrated here, the letter was almost invisible to the camera, because the edges of the letter were defined only by an abrupt change in the direction of motion. $C$, A CD letter was created by switching off all the dots outside the letter. $D$, As for $A$, but dot density was $2 \%$. $E$, As for $B$, but dot density was $2 \%$. $F$, As for $E$ except that all dots outside the letter were stationary. $G$, As for $E$ except that dots outside the letter moved vertically while dots inside the letter moved horizontally.

responses recorded on the computer. Ten trials were then presented at a slower dot speed, and so on until the subject's responses reached chance level. Speed threshold for discriminating leftward from rightward motion was defined as the dot speed for $75 \%$ correct direction discrimination and was estimated from the psychometric function obtained by
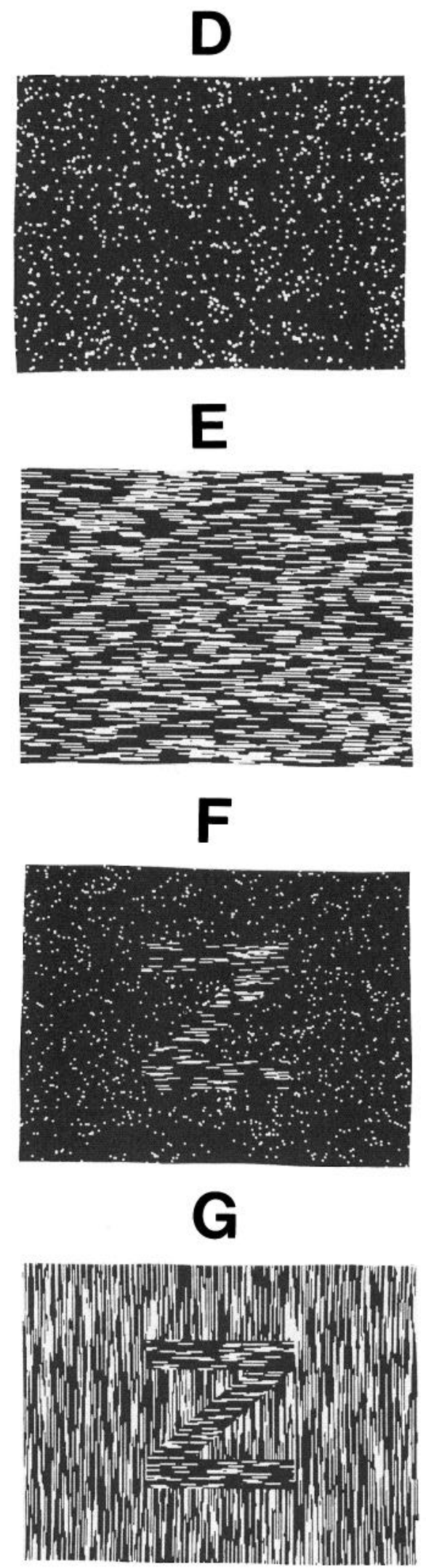

plotting the percentage correct responses (regardless of direction) versus dot speed. Threshold was calculated by the computer on request.

(3) Motion detection. The same dot display was used as for the MD letters except that all the dots either moved in the same direction (i.e., moved coherently) or were stationary. Again, the method of two-alter- 


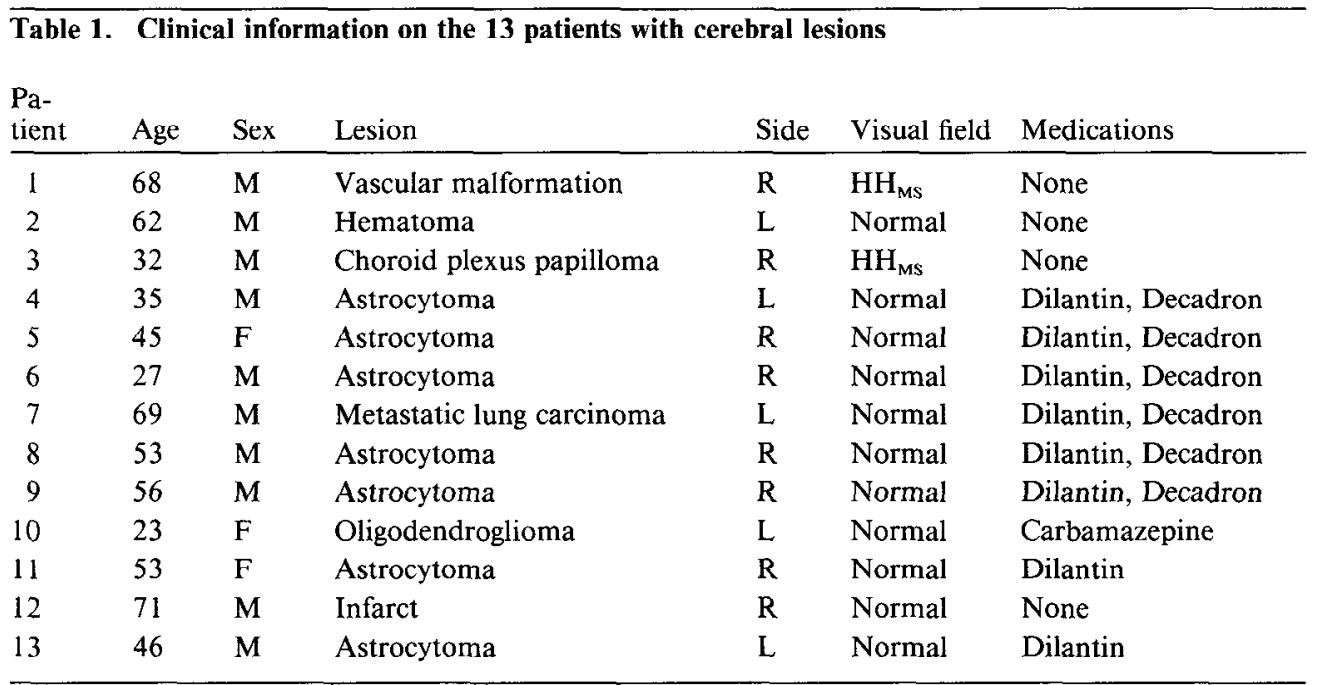

$\mathrm{HH}_{\mathrm{MS}}$ indicates homonymous hemianopia with macular sparing over $5^{\circ}$ from fixation.

native forced choice was used. A trial consisted of two 1 sec presentations separated by an interval of $0.5 \mathrm{sec}$ duration. The dots were stationary during one presentation and moved leftward at fixed speed during the other presentation. The order was random. Subjects were instructed to state whether the dots were moving during the first or the second presentation and to guess if uncertain. Ten trials were presented with the same dot speed, and the subject's responses recorded on the computer. Ten trials were then presented at a slower dot speed, and so on until the subject's responses reached chance level. Speed threshold for detecting lettward motion was defined as the dot speed for $75 \%$ correct responses and was estimated from the psychometric function obtained by plotting the percentage correct responses versus dot speed. Threshold was calculated by the computer on request. Then the entire measurement was repeated for rightward motion. We took motion detection threshold as the mean of the thresholds for leftward and rightward motion.

(4) Contrast-defined solid letters. Snellen line acuity was measured using the chart shown as Figure 4 in Regan (1988) in which lettcr sizes were equally spaced on a logarithmic scale. Letters on successive lines differed in size by a constant ratio of $1:(2)^{1 / 3}=1: 1.26$. The chart was hung on the front of a screen illuminated by tungsten light to a luminance of $100 \mathrm{~cd} / \mathrm{m}^{2}$. Visual acuities (for $75 \%$ correct reading scores) were measured for letters of $96 \%$ and $11 \%$ contrast and, as for stimuli $1-3$ above, were estimated from a plot of the percentage of correct responses versus letter size.

\section{Stimulus duration}

Although all subjects were instructed to keep their gaze directly on the center of the screen, it was possible that some might attempt to "cheat" by looking at the left or right edge of the screen. Especially for stimuli

Table 2. Means, $\mathrm{SD}$, and normal limits for 20 control subjects (20 eyes)

\begin{tabular}{|c|c|c|c|}
\hline & Mean & SD & NL \\
\hline Recognition threshold (degree/sec) & 0.062 & 0.022 & 0.12 \\
\hline Detection threshold (degree/sec) & 0.015 & 0.0090 & 0.038 \\
\hline $\begin{array}{l}\text { Right } / \text { left discrimination threshold } \\
(\text { degree } / \mathrm{sec})\end{array}$ & 0.025 & 0.016 & 0.065 \\
\hline $\begin{array}{l}\text { Motion detection threshold } \\
(\text { degree } / \mathrm{sec})\end{array}$ & 0.029 & 0.012 & 0.059 \\
\hline $96 \%$ contrast Snellen acuity & 1.6 & 0.26 & 0.95 \\
\hline $11 \%$ contrast Snellen acuity & 0.91 & 0.14 & 0.56 \\
\hline
\end{tabular}

Normal limits are given as 2.5 SD from the control group mean. Visual acuities are given as decimal visual acuity. of Iong ( $3-4 \mathrm{sec})$ duration, we had the intuitive impression that it was easier to differentiate moving dots from stationary dots and to differentiate leftward from rightward motion when this tactic was employed because, when the edge of the screen is fixated, the appearance and disappearance of dots seem to be more evident and the edge of the screen provides a nearby stationary reference. In a quantitative invesligation of this question we compared speed thresholds for three control subjects when (1) fixating the center of the screen and (2) when fixating the left edge of the screen. We collected data for two stimulus durations, $3.5 \mathrm{sec}$ and I sec, and concluded that "cheating" did not significantly alter thresholds for either duration, and that any small residual cheating effect was less at the shorter than at the longer duration.

\section{Observers}

Thirteen patients with unilateral cerebral hemispheric lesions performed all the tests described above. The patients' mean age was 49.2 , standard deviation 16.2, and range 23-71 years. One eye was tested in each patient. If Snellen acuities in the two eyes differed, the eye with better acuity was tested. If Snellen acuities were the same, the patient chose which eye to use. All eyes tested had excellent Snellen acuities for highcontrast letters (decimal visual acuity 1.0 to 2.0 , i.e., $6 / 6$ to $6 / 3$ )-all above the lower limit of normality for our control group. The fellow eye was patched. All patients underwent visual field testing by Humphrey perimetry. Patients with corrected Snellen acuity less than $6 / 6$ (i.e., decimal visual acuity less than 1.0) were excluded, as were patients with peripheral visual field defects that extended to within $5^{\circ}$ of the fovea and patients with nystagmus.

Lesions in each of the 13 patients were 10 brain neoplasms, one hemorrhagic arteriovenous malformation, one hypertensive hemorrhage (hematoma), and one infarct (Table 1). Their extent was identified by means of computer-assisted tomography (CT) and traced onto templates from atlases of axial brain anatomy using a procedure described previously by Morrow and Sharpe (1990). The templates were oriented $15^{\circ}$ above the orbitomeatal line, and axial levels were approximately 8 $\mathrm{mm}$ apart. The locations of the lesions were estimated by comparing Figures 2-5 with an atlas of axial brain anatomy (De Armond et al., 1976). The CT investigations had been conducted for clinical reasons, and would have been conducted if the present study had not been carried out. Clinical information for each patient is shown in Table 1.

Twenty age-matched normal subjects served as controls. Their mean age was 45.4 , standard deviation 12.0, and range $26-68$ years. One eye was tested in each subject. All patients and controls provided written consent to the testing after the procedures had been fully explained.

\section{Results}

Controls

Table 2 shows control data for the entire group of 20 control subjects (20 eyes). Normal limits (NL) are shown as 2.5 SDs 


\begin{tabular}{|c|c|c|c|c|c|c|c|}
\hline \multirow[b]{3}{*}{ Patient } & \multirow[b]{3}{*}{ Eye } & \multicolumn{2}{|l|}{ MD letter } & \multirow{3}{*}{$\begin{array}{l}\text { Left vs. } \\
\text { right }\end{array}$} & \multirow{3}{*}{$\begin{array}{l}\text { Motion } \\
\text { vs. static }\end{array}$} & \multirow{2}{*}{\multicolumn{2}{|c|}{ Snellen acuity }} \\
\hline & & Recogni- & & & & & \\
\hline & & tion & Detection & & & $96 \%$ & $11 \%$ \\
\hline 1 & $\mathrm{~L}$ & $0.14^{*}$ & $0.048^{*}$ & 0.032 & 0.029 & 1.1 & $0.49^{*}$ \\
\hline 2 & $\mathrm{R}$ & $0.13^{*}$ & 0.022 & 0.024 & 0.027 & 1.7 & 0.92 \\
\hline 3 & $\mathrm{~L}$ & $0.15^{*}$ & 0.023 & 0.018 & 0.019 & 1.1 & 0.64 \\
\hline 4 & $\mathrm{~L}$ & $0.17^{*}$ & 0.019 & 0.027 & 0.034 & 1.9 & 1.1 \\
\hline 5 & $\mathrm{~L}$ & 0.063 & 0.020 & 0.036 & 0.036 & 1.1 & 0.67 \\
\hline 6 & $\mathrm{R}$ & 0.031 & 0.020 & 0.032 & 0.032 & 2.0 & 0.90 \\
\hline 7 & $\mathrm{R}$ & 0.089 & 0.013 & 0.023 & 0.029 & 1.0 & $0.48^{*}$ \\
\hline 8 & $\mathrm{R}$ & 0.058 & 0.028 & 0.047 & 0.041 & 1.8 & 0.83 \\
\hline 9 & $\mathrm{R}$ & $0.13^{*}$ & 0.018 & 0.026 & 0.037 & 1.2 & 0.72 \\
\hline 10 & $\mathrm{~L}$ & $0.14^{*}$ & $0.063^{*}$ & 0.032 & 0.042 & 1.9 & 1.2 \\
\hline 11 & $\mathrm{R}$ & 0.056 & 0.010 & 0.030 & 0.023 & 2.0 & 1.2 \\
\hline 12 & $\mathrm{R}$ & $0.25^{*}$ & $0.070^{*}$ & 0.047 & 0.050 & 1.4 & $0.56^{*}$ \\
\hline 13 & $\mathrm{~L}$ & 0.076 & 0.033 & 0.045 & 0.035 & $1: 1$ & 0.69 \\
\hline
\end{tabular}

from the mean of this group. All control eyes fell within the 2.5 SD normal range for every test.

\section{Patients}

Table 3 shows test results for the entire group of 13 patients. Speed thresholds for recognizing MD letters were abnormal in seven patients (patients $1,2,3,4,9,10,12$ ). Speed thresholds for detecting letters were also abnormal in three of these seven patients (patients 1, 10, 12). For three of these seven patients the lesion was located in the left hemisphere, and for the remaining four patients the lesion was located in the right hemisphere (Table 1). All other test results were normal for these seven patients except that, for three patients (patients 1,7 , and 12 ), Snellen acuity for letters of $11 \%$ contrast was abnormally low.

Table 3 shows that recognition, detection, and all other speed thresholds were normal in six patients (patients $5,6,7,8,11$, 13). For two of these six patients the lesion was in the left hemisphere, and for the remaining four patients the lesion was located in the right hemisphere (Table 1). All other test results fell within the normal range for these six patients except that, for one patient (patient 7), Snellen acuity for letters of $11 \%$ and $4 \%$ contrast were abnormally low.

An anonymous reviewer suggested that the pattern of visual loss in the seven patients just described might be due to fixation instability or persistent nystagmus. This suggestion can bc rcjected on the following grounds. (1) Clinical examination indicated that none of the patients tested had nystagmus. (2) We measured visual acuity with a line chart whose letters were separated by one letter's width (Regan, 1988). Even a fixation instability that is inappreciable on visual inspection disrupts acuity when this chart is used (Kothe and Regan, 1990), and all of our patients had acuities between $6 / 6$ and $6 / 3$ for this chart. (3) Horizontal eye movements would tend to improve rather than degrade reading performance for MD letters, because such eye movements would cause the retinal images of dots inside and outside the letter to move at different speeds, thus adding a texture cue to the motion cue for figure-ground segregation. This point is illustrated in Figure $1 F$, which shows the retinal image of the Figure $1 E$ stimulus in the extreme case in which the eye tracks the surround dots.

\section{Anatomic correlation}

Figure 2 shows the boundaries of the seven cerebral hemispheric lesions in the seven patients who had abnormal speed thresholds for recognizing MD letters. The hatched areas are the regions of overlap of three or more lesions. Six of the seven patients contributed to the overlap areas at two or more axial levels.

For explanatory purposes, in Figure 3 all the lesions shown in Figure 2 are plotted onto the right hemisphere. The hatched areas are the regions of overlap of three or more lesions. Six of the seven patients contributed to the overlap areas at two or more axial levels. The regions of overlap were in parietotemporal white matter underlying Brodmann areas 18, 19, 37, 39, 21 , and 22 . The black areas indicated by arrows in Figure $3, B$ and $C$, are the regions of overlap of five lesions.

As mentioned above, the ability to detect MD letters was spared in three of the seven patients with elevated speed thresholds for recognizing MD letters. We compared the lesion boundaries in these two subgroups but were unable to identify any consistent difference in either the size, location, or lateralization of the lesion.

Figure 4 shows the boundaries of the six cerebral hemispheric lesions in the six patients whose speed thresholds for recognizing MD letters fell within the normal range. At no axial level did any of these lesions extend into the overlap areas shown in Figures 2 and 3.

Figure 5 shows the boundaries of the three cerebral lesions in the three patients whose visual acuities for low-contrast letters were abnormally poor relative to high-contrast visual acuity (see Table 3 ). These lesions were the three most posteriorly located of all 13 lesions. The hatched region of overlap was located in white matter underlying areas 18 and 19.

\section{Discussion}

Patterns of visual sensory loss in individual patients in relation to the sites of the associated lesions

Our main finding is that a selective elevation of speed threshold for detecting and/or recognizing MD letters was produced by a single large hemispheric parietooccipital brain lesion that involved a discrete region (indicated by hatching in Figs. 2, 3) that underlies Brodmann cortical areas 18, 19, 37, 39, 21, and 

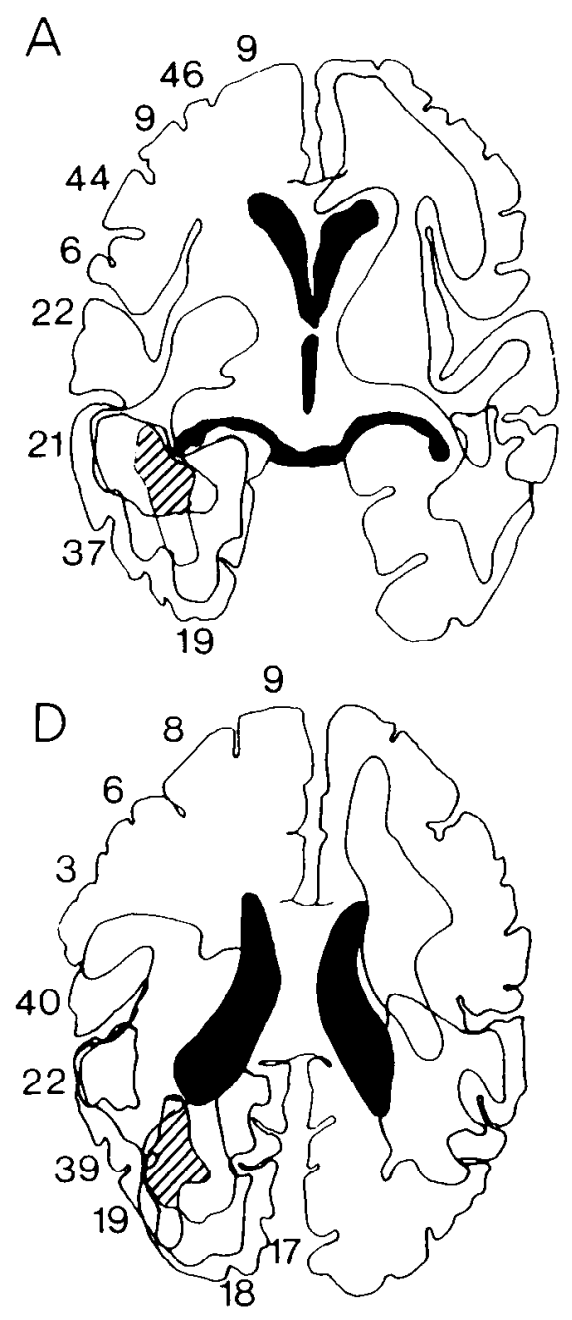
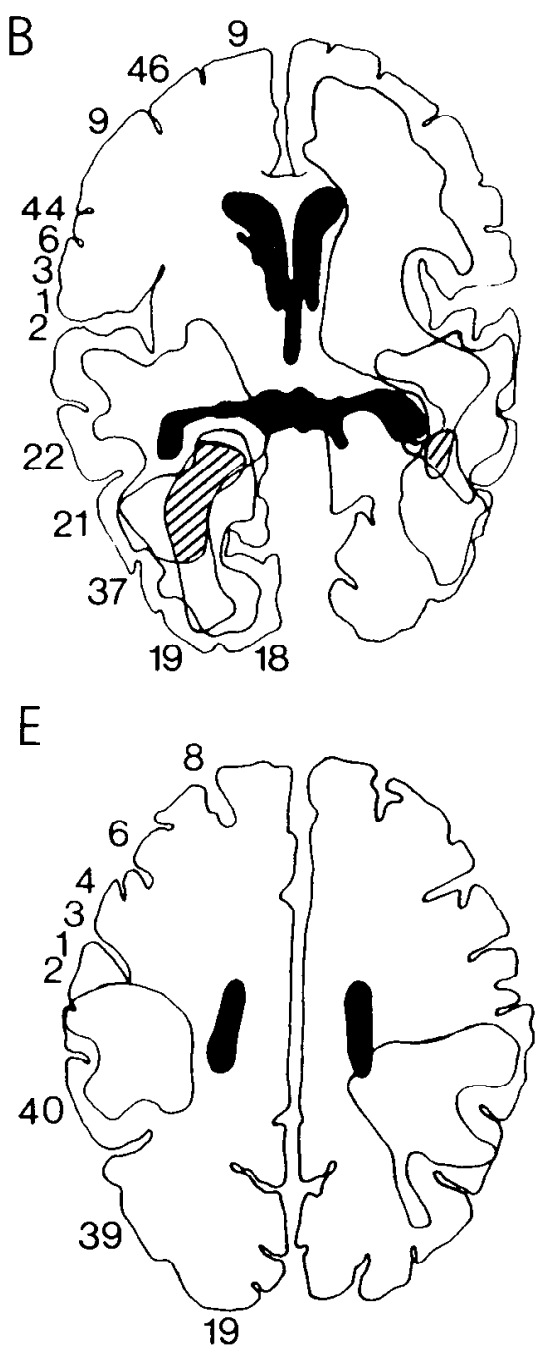

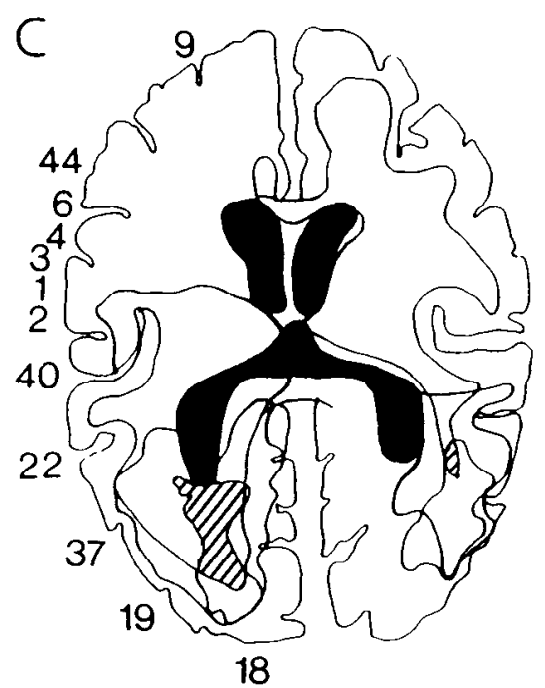

F

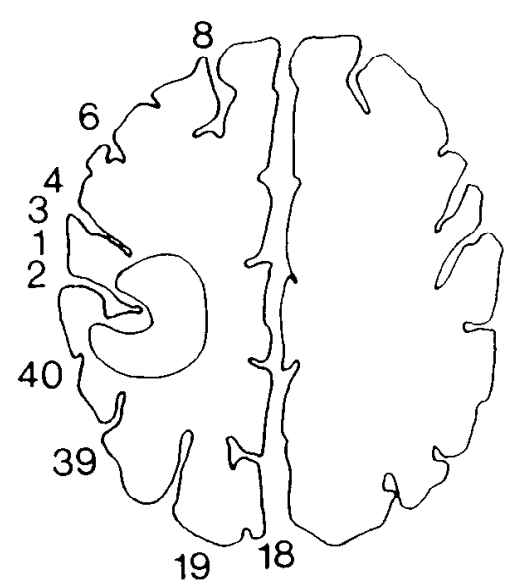

Figure 2. The outlines mark the lesion boundaries delineated by CT in seven patients with unilateral cerebral hemisphere damage who had abnormal speed thresholds for recognizing MD letters. Lesions are plotted onto six templates of axial brain anatomy. The templates represent slices approximately $8 \mathrm{~mm}$ apart, oriented $15^{\circ}$ above the orbitomeatal line. The right hemisphere is on the left side of each slice. Ventricles are marked in solid black. Brodmann numbers of adjacent cortical areas are marked. The hatched areas in the left and right hemisphere indicate overlap between the lesions in three or more patients.

22 in temporoparietal cortex. The hatched area in Figure 3 involves subcortical white matter and extends as far rostrally as the tail of the caudate nucleus.

We confirm a previous report (Giaschi et al., 1991, 1992) that it is possible to experience a failure of the ability to detect and/ or recognize MD letters while speed thresholds for detecting the presence of coherent motion and for discriminating the direction of motion remain within normal limits (though this previous report was restricted to patients with multiple sclerosis). We report here that seven patients with unilateral cerebral lesions showed this pattern of selective visual loss. Because Snellen acuity fell within normal limits for all patients tested, we can exclude a general failure of the ability to recognize letters or word blindness (alexia) as possible explanations for the loss of ability to recognize MD letters.

Of the seven patients who showed a loss of ability to recognize MD letters, four retained normal ability to detect those same letters (type I loss), while three patients showed a loss of ability both to recognize and to detect MD letters (type II loss). Unsurprisingly, no patient had an abnormal detection threshold with spared recognition threshold. To explain the finding that both type I and type II loss occurred, and that both were associated with unimpaired processing of coherent motion, we suggest that motion information is processed in hierarchical sequence in the human visual pathway.

In particular, our evidence is consistent with the hypothesis that motion is processed in the following hicrarchical stages: $1 \mathrm{M}$, direction-specific detection of local motion; $2 \mathrm{M}$, detection of form defined by equal and opposite speeds; and 3M, spatial discrimination and recognition of MD form. Previous evidence (Braddick et al., 1978; Regan, 1982; Regan and Beverley, 1983, 1985 ) is consistent with the hypothesis that luminance contrast is processed in the following hierarchical stages: $1 \mathrm{~L}$, detection of form defined by luminance contrast; and $2 \mathrm{~L}$, spatial discrimination and recognition of luminance-defined form. In terms of this hierarchical processing scheme, there are two possible explanations for our present findings. First, we could assume that motion and luminance signals converge onto a single discrimination/recognition stage (i.e., stages $3 \mathrm{M}$ and $2 \mathrm{~L}$ are the same), in which case we conclude that this common stage remained intact in all patients tested but that motion signals were interrupted between stages $2 \mathrm{M}$ and $3 \mathrm{M}$ for patients $2,3,4$, and 9 

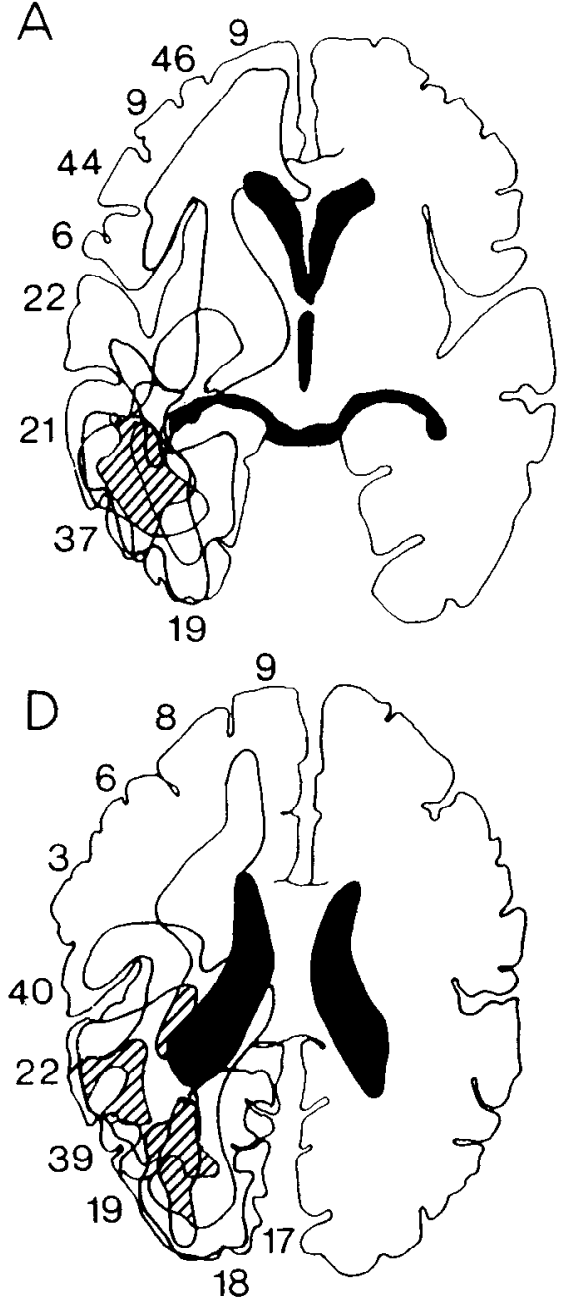

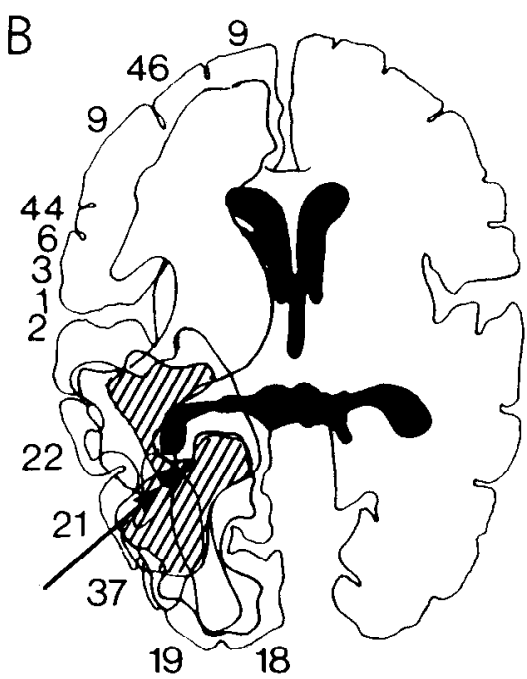

$E$

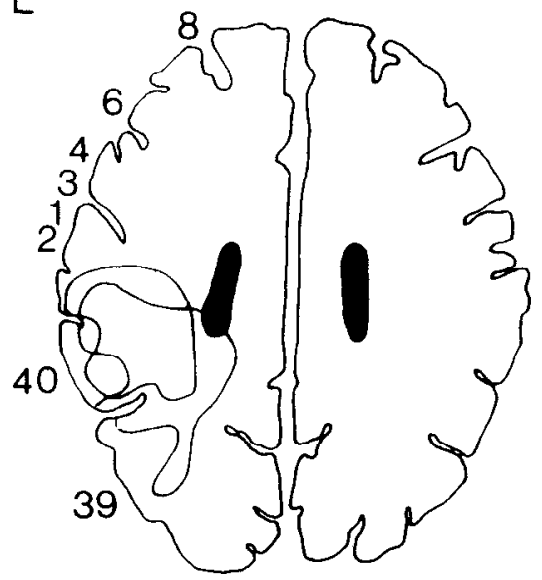

19

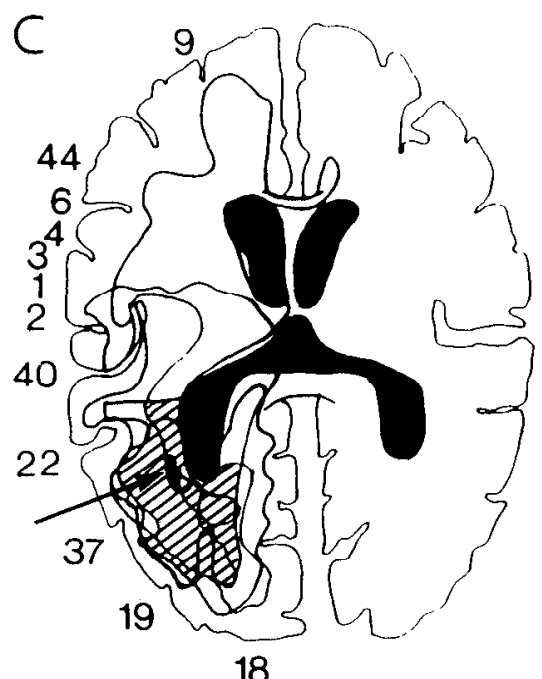

F

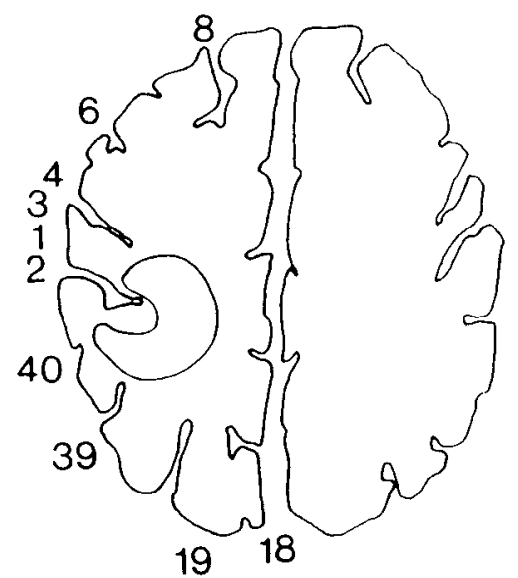

Figure 3. As for Figure 2 except that, for explanatory purposes, all lesions are plotted onto the right hemisphere. Hatching shows regions of overlap of three or more lesions. The solid areas indicated by arrows in $B$ and $C$ indicate overlap between the lesions in five patients.

(who could detect, but not recognize, MD letters). For patients 1,10 , and 12 (who could neither recognize nor detect MD letters), we conclude that stage $2 \mathrm{M}$ was dysfunctional and/or motion signals were interrupted between stages $1 \mathrm{M}$ and $2 \mathrm{M}$. The second possible explanation assumes that there are two discrimination/ recognition stages (i.e., $3 \mathrm{M}$ and $2 \mathrm{~L}$ are separate), in which case stage $3 \mathrm{M}$ was inactive in patients $2,3,4$, and 9 while both $3 \mathrm{M}$ and $2 \mathrm{M}$ were inactive in patients 1,10 , and 12 .

Qualitatively, at least, our evidence provides no indication that the selective loss of ability to process MD form depends on whether the unilateral lesion is in the left or the right hemisphere. Of the seven patients who showed this pattern of sensory loss, three had a lesion in the left hemisphere and four in the right hemisphere. (This discussion is restricted to foveal vision. It is possible that asymmetric visual loss might be revealed by using motion stimuli similar to stimuli $1-3$ in Materials and Methods-though modified to allow for reduced acuity-to compare extrafoveal vision in the contralateral and ipsilateral hemifields.) We note that the presence of a cerebral hemispheric lesion without regard to its site was not sufficient to produce a selective failure of the ability to detect and/or recognize MD letters. The basis for this conclusion is that speed thresholds for detecting and recognizing MD letters fell within the normal range for six patients, all of whom had unilateral cerebral lesions (Fig. 4), none of which invaded the hatched areas in Figure 2 and 3 .

Most of our patients took anticonvulsant drugs (see Table 1). It could be argued that, because these medications degrade smooth ocular pursuit of moving targets (Sharpe and Morrow, 1988), they might have contributed to defective motion processing. This argument is ruled out, however, by the finding that several of the patients who took anticonvulsant drugs had normal motion thresholds for recognizing MD letters.

Three patients showed a loss of low-contrast visual acuity relative to high-contrast acuity. Bearing in mind that a loss of ability to read low-contrast letters with spared Snellen acuity seems to be common in patients with a variety of neurological disorders including multiple sclerosis, Parkinson's disease, and amblyopia (Regan and Neima, 1983, 1984; Regan and Maxner, 1986, 1987; Drucker et al., 1988; Regan, 1988; Sokol ct al., 1990 ), it is intriguing that only 3 of our 13 patients with cerebral lesions showed this loss of low-contrast acuity. It may be significant that the lesions in these three patients extended farther posteriorly than any of the other 10 lesions. Figure 5 shows that the region of overlap of the three lesions was located in white matter underlying areas 18 and 19. 

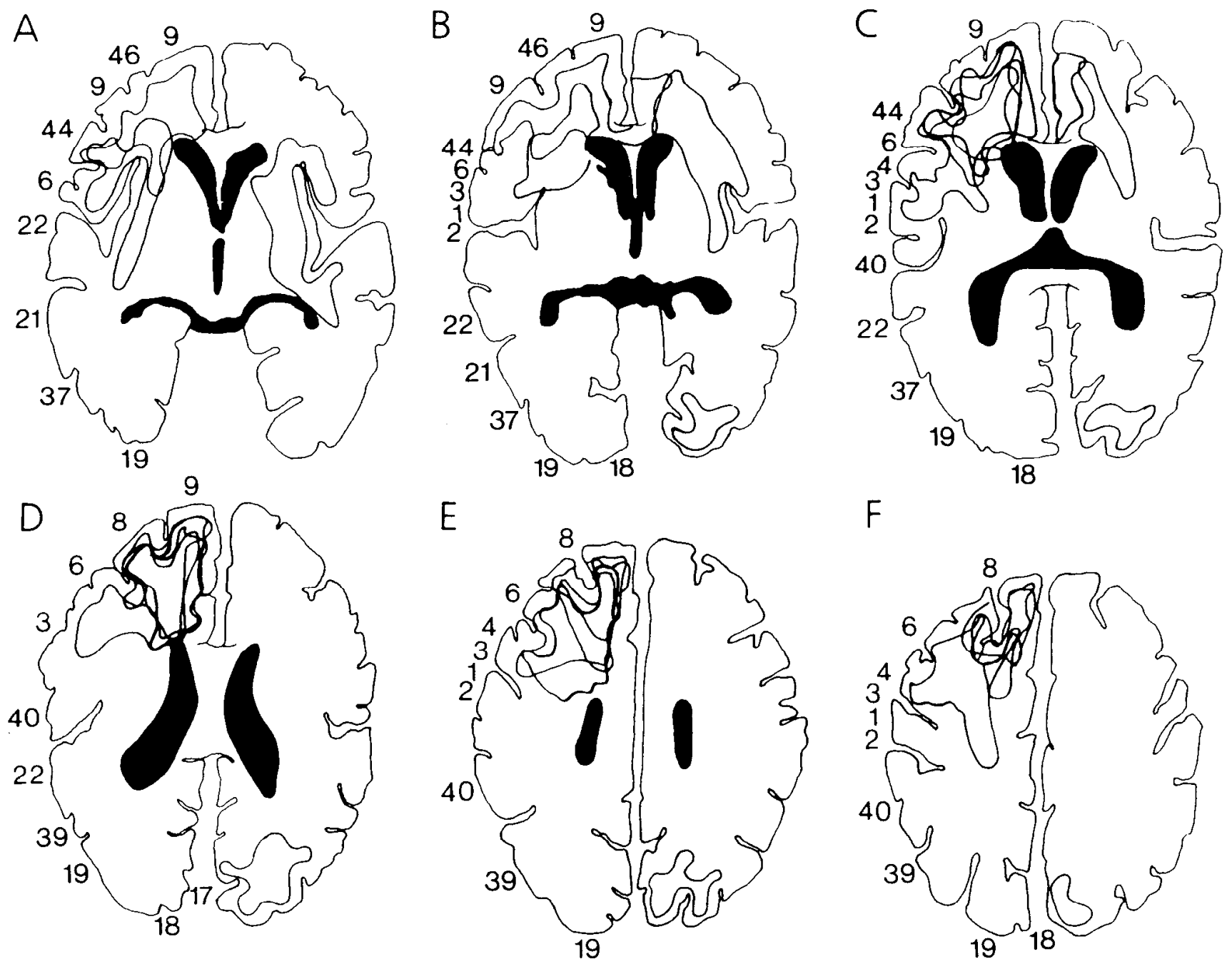

Figure 4. Lesion boundaries in six patients whose speed thresholds for recognizing MD letters fell within the normal range. Other details were as for Figure 2.

\section{Different kinds of motion "blindness"}

Before discussing the physiological implications of our findings, we should distinguish between different kinds of motion "blindness" and define the difference between coherent motion stimuli and noncoherent motion stimuli. Until recently, almost the only kinds of motion stimuli used to investigate vision in clinical and basic research alike were (1) motion of an isolated object, and (2) bodily flow of a texture or dot pattern within a stationary frame. These two kinds of stimuli are examples of coherent motion stimuli. Clinical studies were almost entirely restricted to measuring a patient's ability to detect (as distinct from discriminate) the motion of such stimuli. Although, even in normally sighted subjects, selective blindness to coherent motion in depth is common (Richards and Regan, 1973; Regan et al., 1986; Hong and Regan, 1989), a selective loss of the ability to detect coherent frontal plane motion seems to be rare, and confirmed cases are reported only occasionally (Zihl et al., 1983) [though a nonselective depression of many visual sensitivities including sensitivity to frontal plane motion is often associated with hemispheric pathology (Teuber et al., 1960)].

During the last decade, the study of psychophysical responses to coherent motion has been extended to include measurements of speed discrimination and direction discrimination (McKee et al., 1986), and several new tests of visual motion processing have been introduced. One of these new tests measures the ability to detect and spatially discriminate camouflaged MD form (Regan and Beverley, 1984; Regan, 1986, 1989a; Vaina, 1989; Banton and Levi, 1990; Regan and Hamstra, 1990, 1991, 1992). Another new test measures the ability to detect the presence of global motion and to discriminate its direction for a dot pattern that contains dots moving in different directions (Morgan and Ward, 1980; Williams and Sekuler, 1984; Zucker, 1984; Newsome and Pare, 1988; Siegel and Anderson, 1988; Downing and Movshon, 1989). One-dimensional or two-dimensional expansion or contraction is a third kind of noncoherent motion, and there is psychophysical evidence that the human visual pathway contains neurons selectively sensitive to this kind of noncoherent motion (Regan and Beverley, 1978, 1980) as well as microelectrode evidence that such neurons exist in cat (Regan and Cynader, 1979) and monkey (Zeki, 1974; Tanaka and Saito, 1989; Tanaka et al., 1989) visual cortex.

All these new kinds of stimuli differ from the older kind of coherent-motion stimuli in a single common respect. Suppose that each point in the visual field is analyzed by a separate "local motion detector" (Santen and Sperling, 1984, 1985; Reichardt, 

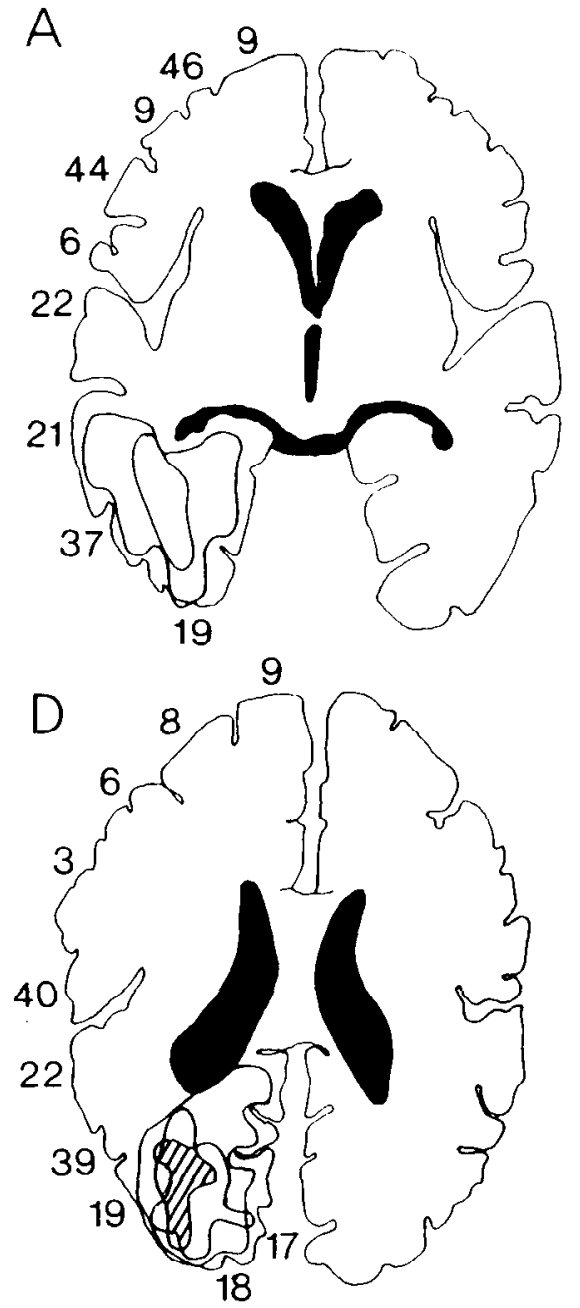
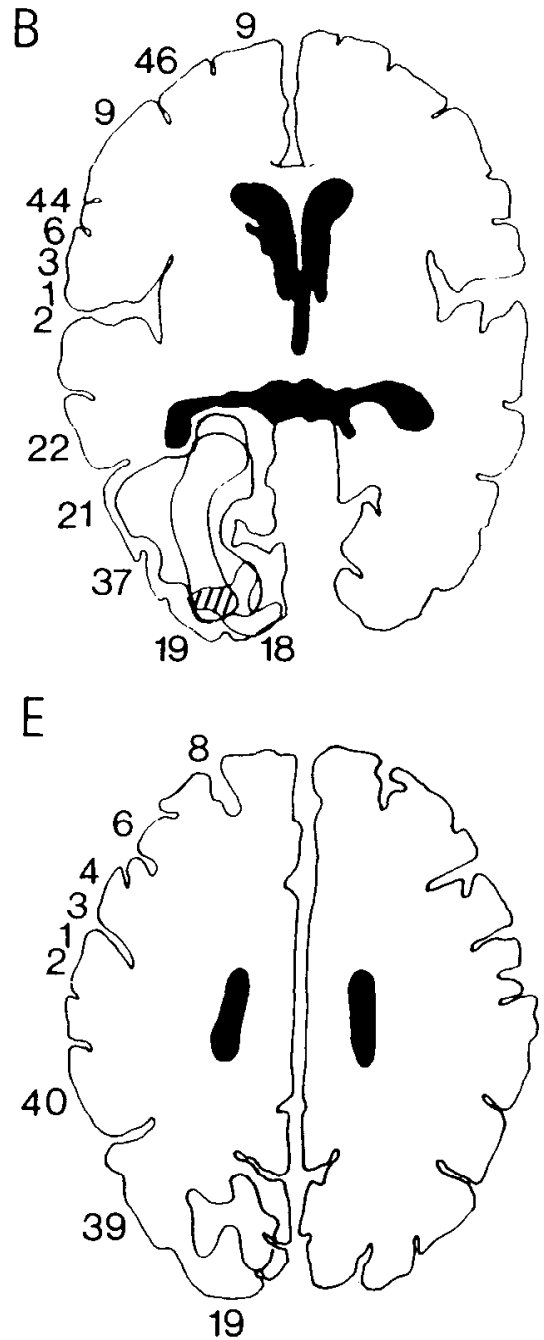

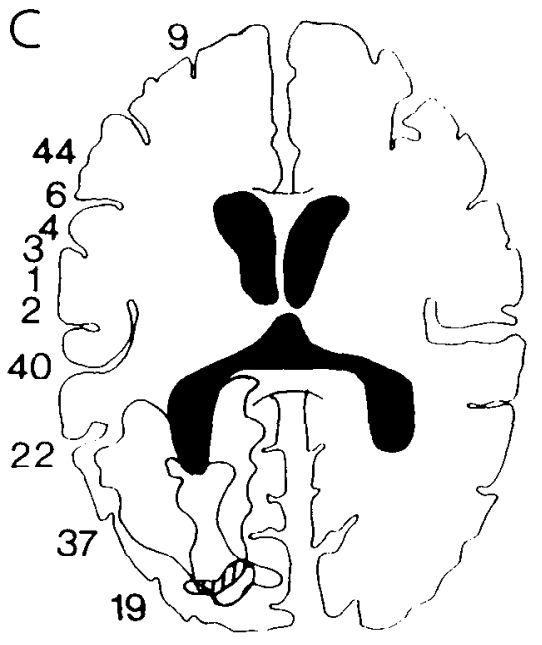

18

$F$

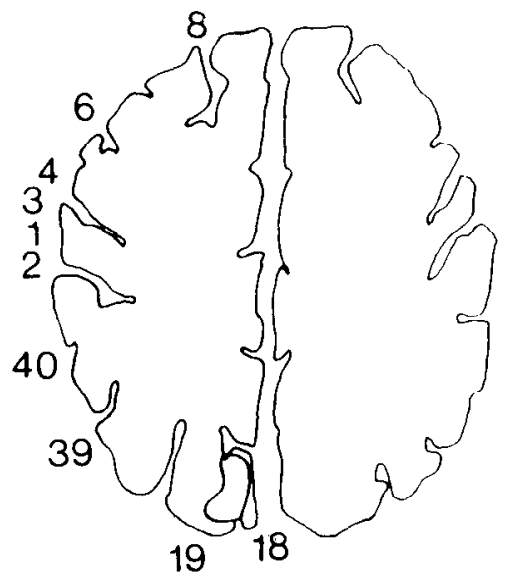

Figure 5. Lesion boundaries for three patients whose low-contrast visual acuity was abnormally low. The hatched area indicates the overlap region of the three lesions.

1986) and that the response of any given local motion detector is not affected by the activity of any other local motion detector. In principle, the presence of motion and the direction of motion of a coherently moving texture could be signaled correctly by a single one of these local motion detectors. However, this is not the case for any of the newer kinds of stimuli mentioned above. For example, the overall direction of motion of a dot pattern whose motion is noncoherent cannot be estimated from the motion of any single dot, because the speeds and/or directions of motion of different dots may be quite different: correct psychophysical judgements require that the motion of many dots be taken into account. Therefore, spatially integrative (i.e., global) processing is necessary for consistently correct psychophysical responses (Morgan and Ward, 1980; Vaina, 1989). The same situation obtains when we consider MD form. Merely to detect a camouflaged shape entirely on the basis of motion contrast requires the visual system to compare the speed and direction of motion at different locations in the visual field. In other words, figure-ground segregation cannot be achieved entirely on the basis of local processing of motion: spatially integrative (i.e., global) processing is required also (Regan and Beverley, 1984). And the correct performance of tasks such as letter recognition, shape discrimination, and orientation discrimination for MD form require still further spatially integrative processing: detection is not enough for the correct performance of these tasks (Regan, 1982, 1986; Regan et al., 1982; Regan and Beverley, $1983,1984,1985)$.

\section{Physiological implications}

Many caveats attend any attempt to associate the site of a lesion with a loss of visual function: it does not necessarily follow that, if a lesion in a given location $L$ produces a selective loss of visual function $X$, neural activity at location $L$ is the physiological basis of visual function $X$ (Glassman, 1978). To support such an assertion, one would need to deny that visual function $\mathrm{X}$ was determined by the pattern of activity at several locations, one of which was location L. Furthermore, if several locations were interconnected so as to form a system, the function $X$ might be a property of the system as a whole. And if this distributed system were nonlinear, the system property $X$ may not be evidenced by any of the component elements of the system alone, including the component located at $L$ (Blaquiere, 1966; Marmarelis and Marmarelis, 1978; Mountcastle, 1979; Regan, 1991a). Therefore, rather than suggesting that the areas of overlap in Figures 2 and 3 "mediate" recognition of MD form, we offer that the areas "are necessary" for this visual function. We 


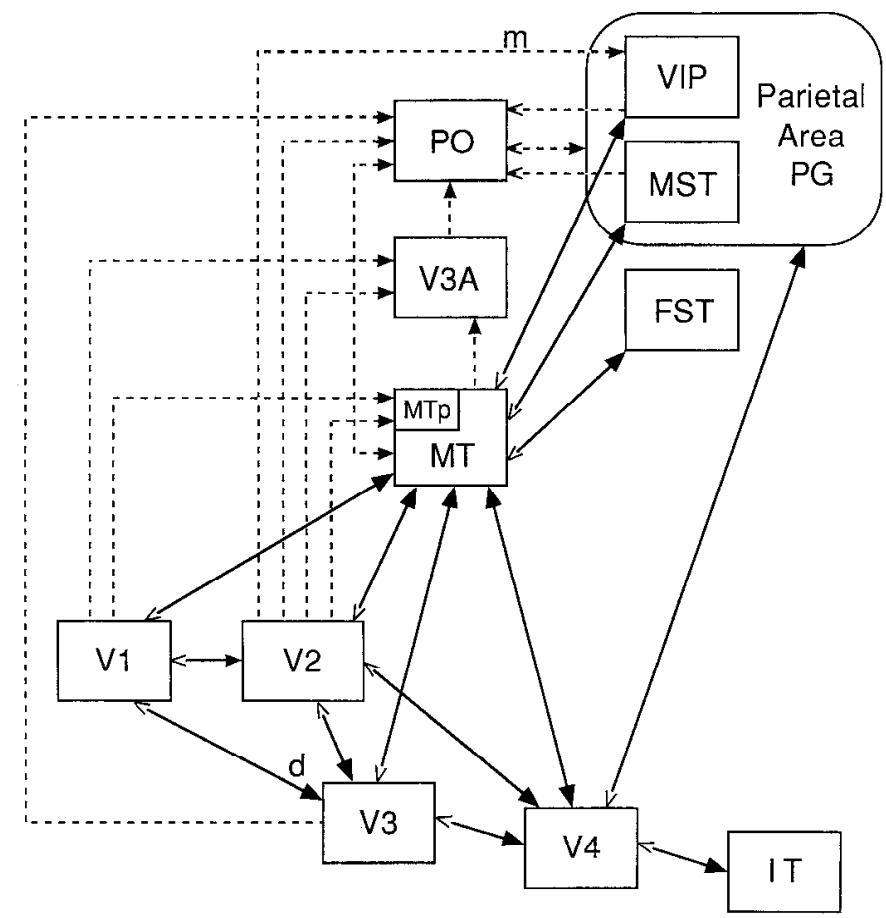

Figure 6. This figure illustrates the hypothesis that striate cortex (VI) is the source of two pathways. One, directed dorsally into the parietal lobe, is important for the processing of motion information, for the comprehension of spatial relationships, and for visual guidance of movement. The second, directed ventrally into the temporal lobe, is important for the processing of color and spatial form and for object recognition. From Desimone et al. (1985), reprinted with permission.

note that our present evidence falls well short of what would be required to support the first hypothesis just mentioned. For example, because they involved white matter, the lesions may have interrupted signals passing through the overlap region to more central location(s) whose neural activity was the physiological basis for function $X . \Lambda$ second caveat is that in no patient was the lesion restricted entirely to the region of overlap. Therefore, we cannot be sure that a lesion to the overlap area alone would have produced a selective loss of ability to recognize MD form. In particular, we cannot deny that to produce this selective loss it is necessary that an extensive volume of parietooccipital white matter must be damaged (bearing in mind that the selective loss was not observed in any of the six patients whose extensive lesions, shown in Fig. 4, did not include the areas of overlap shown in Figs. 2 and 3 ).

Turning to the experimentally demonstrated properties of visual pathway neurons in nonhuman primate, it is known that neurons sensitive to the direction of coherent motion have been found in areas V1, V2, and V3 of monkey visual pathway (De Yoe and Van Essen, 1985; Hawken et al., 1988), though it is not until the prestriate middle temporal area (MT) that neurons showing a strong preference for one direction of coherent motion exist as a common type (Dubner and Zeki, 1971; Zeki, 1974; Maunsell and Van Essen, 1983; Albright, 1984; Van Essen, 1985; Saito et al., 1986; Tanaka et al., 1986; Maunsell and Newsome, 1987). But even then, directionally selective neurons are not sufficient to account for the detection of a camouflaged letter that is rendered visible by motion alone. The detection of the MD letters used in this study requires neurons that respond to the coincidence of texture moving rightward at one location in the visual field and texture moving leftward at a different location in the visual field.

Behavioral evidence that area MT is important for discriminating the direction of motion in monkey includes the findings that microstimulation of a cluster of MT neurons can bias a monkey's perceptual judgements of motion direction toward the neurons' preferred direction of motion (Saltzman et al., 1990). On the other hand, bilateral lesions of MT/MST (medial superior temporal area) did not affect discrimination between gratings moving coherently in opposite directions, though these lesions "devastated directional discrimination" for global motion of noisy random-dot patterns (Newsome and Pare, 1988; Merigan et al., 1991c; Pasternak et al., 1991).

Neurons sensitive to opponent motion exist in monkey visual cortex, in area MT (Allman et al., 1985; Van Essen, 1985), in the more central MST area that receives input from MT, and also in parietal area $7 \mathrm{a}$ that receives input from MST (Motter and Mountcastle, 1981; Maunsell and Van Essen, 1983; Saito et al., 1986; Tanaka et al., 1986). Neurons that respond to an MD bar (i.e., that can detect an MD bar) have been found in area MT as well as in areas MST and 7a (Allman et al., 1985; Saito et al., 1986; Tanaka ct al., 1986). These neurons might provide a physiological basis for the detection of MD letters. However, the recognition of MD letters requires still further neural processing. Little can be said about a possible physiological basis for recognition, because no studies have yet been reported on correlations between an alert, behaving monkey's performance in a shape recognition task for $\mathrm{MD}$ form and the simultaneously recorded firing of single cells in prestriate cortex.

It has been proposed that, in monkey, a predominantly $M$ (magnocellular)-stream pathway that passes into the parietal lobe through cortical area V1 and then through areas MT and MST to area $7 \mathrm{a}$ is important for the perception of motion, while a parallel predominantly $P$ (parvocellular)-stream pathway that passes into the temporal lobe through cortical areas V1 and V4 is important for the perception of color and form (Van Essen and Maunsell, 1983; Desimone et al., 1985; Van Essen, 1985; Maunsell and Newsome, 1987; De Yoe and Van Essen, 1988; Merigan and Maunsell, 1990; Merigan et al., 1991a,b). There are several analogies between this hypothesis and the hypothesis that the human visual pathway contains two parallel pathways passing through striate cortex, one of which (the dorsal pathway) processes the "where" while the other (the ventral pathway) processes the "what" of stimulus attributes (Ungerleider and Mishkin, 1982). Figure 6 illustrates this parallel pathway concept. Evidence that in monkey, the $\mathrm{M}$-stream is relatively important for the detection of MD form was reported by Schiller et al. (1990), who investigated the differential effects of lesions restricted to the magnocellular or to the parvocellular layers of the LGN on the behavioral responses of monkeys to a variety of visual stimuli.

If one expresses the concept of parallel physiological pathway for motion and for color in an extreme either/or manner, the results of our series of studies on the detection, spatial discrimination, and recognition of MD form might seem difficult to relate to physiological knowledge of the monkey visual pathway: as mentioned above, neurons sensitive to oppositely directed motion are required to extract $\mathrm{MD}$ form, and such neurons are not found before area MT - far along the so-called motion pathway. On the other hand, the physiologists who put forward this particular parallel-processing hypothesis were careful to avoid suggesting an extreme "either/or" division of function between 
the two pathways for motion and form (Desimone et al., 1985; Van Essen, 1985; Maunsell and Newsome, 1987; De Yoe and Van Essen, 1988). Also, the experimental basis for the original hypothesis did not include physiological data on the responses to MD form.

One way of linking our present findings to animal evidence for the parallel processing of motion and form rests on the evidence that there are many interconnections between cortical areas in the so-called motion and form pathways, some of which descend from prestriate areas in the motion pathway to striate cortex (Desimone et al., 1985; Van Essen, 1985; Van Essen et al., 1990). In particular, we suggest that interconnections between the two pathways may be important for the detection and recognition of MD form. In all seven patients who lost ability to recognize MD letters, the responsible lesions involved white matter and may have interrupted interconnections between the homologs of areas in the MT/MST/7a pathway and of areas in the V1/V4/IT pathway.

By analogy with behavioral findings in monkey (Pasternak et al., 1991), we assume that the human equivalent of MT/MST is necessary for spatially integrative (i.e., global) motion processing. We conclude, therefore, that the human equivalent of MT/MST was not totally dysfunctional in the four patients who retained normal ability to detect $\mathrm{MD}$ form while losing ability to recognize MD form (type I loss). Following this line of argument, in the three patients who had elevated thresholds for both detecting and recognizing MD form (type II loss), the human equivalent of MT/MST may have been at least partly dysfunctional [or signals from MT to more central location(s) were interrupted; see above]. By analogy with monkey data (Pasternak et al., 1991), we further conclude that, because all seven patients just discussed retained normal thresholds for detecting the presence of coherent motion and for discriminating its direction, motion processing was substantially unaffected in the more distal cortical areas that feed MT (e.g., areas V1, V2, and V3).

However, these suggestions can only be tentative, because part of the animal evidence is lacking. The monkey data just cited is restricted to neural properties in areas of monkey visual cortex, and with the interconnections between cortical areas. It is known, however, that at least 20 subcortical structures project directly to visual cortex and that in some cases (e.g., the connections between claustrum and cortex) the connections are reciprocal and organized in a precise point-to-point fashion, thus preserving the retinotopic projection (Tigges and Tigges, 1985; Sherk, 1986). In view of these facts, it seems unlikely that a complete understanding of the relation between structure and function in primate visual pathway will be achieved without taking into account the reciprocal interconnections between cortex and subcortical structures. In particular, the (at least) nine visual areas and (at least) 20 subcortical structures constitute a distributed system, whose system properties presumably underlie visual perception (Mountcastle, 1979). A glance at Figures 2-5 brings out the point that the lesions shown in these figures quite probably interrupted some of the interconnections between cortex and subcortical structures. Therefore, although it has been possible to discuss the results of other studies (Vaina, 1989; Baker et al., 1991) entirely in terms of the properties of cortical areas and the connections within cortex, it would not be appropriate to do so in the present article. The relevance of this point is that, with the possible exceptions of the interconnections between cortex and the LGN and superior colliculus, our current knowledge of the role of cortical-subcortical visual connections in visual perception is sparse (Tigges and Tigges, 1985; Regan, 1989b). Finally, we note that, in the context of distributed systems, it is intriguing that a parietotemporal lesion in either left or right hemisphere produced a selective loss of ability to recognize MD letters. This implies that the distributed system whose properties underlie the recognition of foveally viewed MD form involves structures in both hemispheres.

\section{Comparison with previous work on motion blindness}

A series of intensive studies on a single patient with bilateral damage in the superior temporal region have documented poor performance on several motion-related visual tasks. The crucial finding of the first study was that the patient's performance was normal on several perceptual tasks that did not involve motion. These tasks included Snellen and Vernier acuity, temporal resolution, stereopsis, and color discriminations (Zihl et al., 1983). Zihl et al. pointed out that the location of the lesion was in the general topographic vicinity corresponding to area MT in the monkey. A later article reported that the patient's contrast threshold for discriminating the direction of motion of a grating was severely elevated, although contrast threshold for detecting the grating was only slightly elevated, even for moving gratings (Hess et al., 1989). Hess et al. suggested that the patient's visual loss was for judgements of stimulus motion attributes rather than being a reduced sensitivity to moving stimuli per se. On the other hand, the patient performed well on directional discrimination of a smoothly and coherently drifting random dot pattern (though only over a considerably more restricted range of velocities than in the normal observer). More recently, Baker et al. (1991) tested the same patient's ability to discriminate the direction of motion using a random-dot, variable-coherence, limited-lifetime stimulus. They found that the presence of even a small percentage of stationary (noise) dots was enough to disrupt totally the patient's ability to discriminate the direction of moving (signal) dots. Baker et al. concluded that the patient's failure of directional discrimination was caused by the presence of noisc dots rather than by the bricf dot lifetimes, and suggested that a function of prestriate cortex is the interpretation of visual stimuli with poor signal-to-noise ratios. Visual responses to MD form were not investigated, and the possible role in the processing of motion of reciprocal connections between cortex and subcortical nuclei that we discuss above was not treated in the reports just outlined in which discussion focused on the roles of cortical areas.

A study of smooth pursuit-which requires detection of motion-identified defective ipsilateral smooth pursuit, analogous to the directional pursuit defect caused by destruction of simian area MST and the foveal area of MT (Durstellar and Wurtz, 1988). The confluence of lesions in patients involved cortical areas 39,37 , and 19 , and underlying white matter, suggesting that they contain homologs of areas MST and foveal MT (Morrow and Sharpe, 1990). The lesions were close to the region of lesion overlap in the present study (compare our Fig. 3 with Morrow and Sharpe, 1990, their Figs. 4, 5).

Examples of selective loss of other aspects of motion processing were reported by Vaina (1989) in a study of 18 patients. It was stated that each patient had undergone a unilateral stroke limited to the posterior brain involving tissue in the occipital, parietal, or temporal areas. These stroke patients showed selective loss of motion perception. Vaina reported that the right occipitotemporal group could detect two-dimensional MD tar- 
gets, but could not identify the shape of the targets, while the right occipitoparietal group and the left hemisphere group showed no deficit in the ability to identify the shape of MD targets. This conclusion seems to conflict with our present finding that, of seven patients with impaired ability to recognize the shapes of MD letters, three had unilateral lesions in the left hemisphere and four in the right hemisphere. On the other hand, from the data provided in Vaina's report, it is difficult to compare the sites of brain damage in Vaina's patients with the sites of the lesions shown in Figures 1-3.

\section{References}

Albright TD (1984) Direction and orientation selectivity of neurons in visual area $M T$ of the macaque. J Neurophysiol 52:1106-1130.

Albright TD, Chaudhuri A (1989) Orientation selective responses to motion contrast boundaries in macaque. Soc Neurosci Abstr 15:32.

Allman J, Miezin F, McGuiness EL (1985) Direction- and velocityspecific responses from beyond the classical receptive field in the middle temporal visual area (MT). Perception 14:105-126.

Baker CL, Hess RF, Zihl J (1991) Residual motion perception in a "motion-blind" patient, assessed with limited-lifetime random dot stimuli. J Neurosci 11:454-461.

Banton T, Levi DM (1990) Vernier localization in the motion system. Invest Ophthalmol Vis Sci [Suppl] 31:90.

Bergen JR (1991) Theories of visual texture perception. In: Spatial vision (Regan D, ed), pp 114-134. London: Macmillan.

Blaquiere A (1966) Nonlinear systems analysis. New York: Academic.

Braddick OJ, Campbell FW, Atkinson J (1978) Channels in vision: basic aspects. In: Handbook of sensory physiology (Held R, Leibowitz H, Teuber H-L, eds), pp 3-38. Berlin: Springer.

Brain WR, Walton JN (1969) Brain's diseases of the nervous system, 7th ed, $p$ 103. London: Oxford UP.

Cavanagh P, Arguin M, Treisman A (1990) Effect of surface medium on visual search for orientation and size features. J Exp Psychol 16: $479-491$.

De Armond SJ, Fusco MM, Dewey MM (1976) Structure of the human brain. New York: Oxford UP.

Desimone R, Schein SJ, Moran J, Ungerleider LG (1985) Contour, color and shape analysis beyond the striate cortex. Vision Res 25: $441-452$.

De Yoe EA, Van Essen DC (1985) Segregation of efferent connections and receptive field properties in visual area $\mathrm{V} 2$ of the macaque. Nature 317:58-61.

De Yoe EA, Van Essen DC (1988) Concurrent processing streams in monkey striate cortex. Trends Neurosci 11:219-226.

Downing CJ, Movshon JA (1989) Spatial and temporal summation in the detection of motion in stochastic random dot displays. Invest Ophthalmol Vis Sci [Suppl] 30:72.

Drucker MD, Savino PJ, Sergott RC, Bosley TM, Schatz NJ, Kubilis PS (1988) I ow-contrast letter charts to detect subtle neuropathies. Am J Ophthalmol 105:141-145.

Dubner R, Zeki SM (1971) Response properties and receptive fields of cells in an anatomically defined region of the superior temporal sulcus. Brain Res 35:528-532.

Dursteller MR, Wurtz RH (1988) Pursuit and optokinetic defects following chemical lesions of cortical areas MT and MST. J Neurophysiol 60:940-965.

Giaschi D, Regan D, Kothe A, Hong XH, Sharpe JA (1991) Multiple sclerosis can degrade detection and/or discrimination of motion-defined form while sparing motion sensitivity. Invest Ophthalmol Vis Sci [Suppl] 32:1282.

Giaschi D, Regan D, Kothe A, Hong XH, Sharpe JA (1992) Motiondefined letter detection and recognition in patients with multiple sclerosis. Ann Neurol, in press.

Glassman RB (1978) The logic of the lesion experiment and its role in the neural sciences. In: Recovery from brain damage (Finger $\mathrm{S}$, ed), pp 3-31. New York: Plenum.

Hawken MJ, Lund JS, Parker AJ (1988) Laminar organization and contrast sensitivity of direction-selective cells in the striate cortex of the old world monkey. J Neurosci 8:3541-3548.

Hess RF, Baker CL, Zihl J (1989) The "motion-blind" patient: lowlevel spatial and temporal filters. J Neurosci 9:1628-1640.
Hong XH, Regan D (1989) Visual field defects for unidirectional and oscillatory motion in depth. Vision Res 29:809-819.

Kothe AC, Regan D (1990) The component of gaze selection/control in the development of visual acuity in children. Optom Vision Sci 68:770-778.

Kothe AC, Regan D, Sharpe JA (1990) Motion blindness and insensitivity in patients with multiple sclerosis. Invest Ophthalmol Vis [Suppl] Sci 31:1368.

Marmarelis PZ, Marmarelis VA (1978) Analysis of physiological systems: the white noise approach. New York: Plenum.

Maunsell JH, Newsome WT (1987) Visual processing in monkey extrastriate cortex. Annu Rev Neurosci 10:363-401.

Maunsell JH, Van Essen DC (1983) Functional properties of neurons in middle temporal visual area of the macaque monkey. 1 . Selectivity for stimulus direction, speed and orientation. J Neurophysiol 49: $1127-1147$.

McKee SP, Silverman G, Nakayama K (1986) Precise velocity discrimination despite random variations in temporal frequency and contrast. Vision Res 26:609-619.

Merigan WH, Maunsell JHR (1990) Macaque vision after magnocellular lateral geniculate lesions. Vis Neurosci 5:347-352.

Merigan WH, Katz LM, Maunsell JHR (1991a) The effects of parvocellular lateral geniculate lesions on the acuity and contrast sensitivity of macaque monkeys. J Neurosci 11:994-1001.

Merigan WH, Byrne CE, Maunsell JHR (1991b) Does primate motion perception depend on the magnocellular pathway? J Neurosci 11: 3422-3429.

Merigan WH, Pasternak T, Polashenski W, Maunsell JHR (1991c) Permanent deficits in speed discrimination after MT/MST lesions in a macaque monkey. Invest Ophthalmol Vis Sci [Suppl] 32:824.

Morgan M (1991) Hyperacuity. In: Spatial vision (Regan D, ed), pp 87-113. London: Macmillan.

Morgan MJ, Ward R (1980) Conditions for motion flow in dynamic visual noise. Vision Res 20:431-435.

Morrow MJ, Sharpe JA (1990) Cerebral hemispheric localization of smooth pursuit asymmetry. Neurology 40:284-292.

Motter BC, Mountcastle VB (1981) The functional properties of the light-sensitive neurons of the posterior parietal cortex studied in waking monkeys: foveal sparing and opponent vector organization. $\mathrm{J}$ Neurosci 1:3-26

Mountcastle VB (1979) An organizing principle for cerebral functions: the unit module and the distributed system. In: The neuroscience third study program (Schmidt FO, Woden FG, eds), pp 21-42. New York: Plenum.

Newsome WT, Pare EB (1988) A selective impairment of motion perception following lesions of the middle temporal visual area (MT). J Neurosci 8:2201-2211.

Pasternak T, Maunsell JHR, Polashenski W, Merigan WH (1991) Deficits in global motion perception after MT/MST lesions in a macaque. Invest Ophthalmol Vis Sci [Suppl] 32:824.

Regan D (1982) Visual information channeling in normal and disordered vision. Psychol Rev 89:407-444.

Regan D (1986) Form from motion parallax and form from luminance contrast: vernier discrimination. Spatial Vis 1:305-318.

Regan D (1988) Low-contrast letter charts and sinewave grating tests in ophthalmological and neurological disorders. Clin Vis Sci 2:235250.

Regan D (1989a) Orientation discrimination for objects defined by relative motion and objects defined by luminance contrast. Vision Res 29:1389-1400.

Regan D (1989b) Human brain electrophysiology, pp 302-363. New York: Elsevier.

Regan D (199la) A brief review of some of the stimuli and analysis methods used in spatiotemporal vision research. In: Spatial vision (Regan D, ed), pp 1-42. London: Macmillan.

Regan D (1991b) Spatial vision for objects defined by colour contrast, binocular disparity and motion parallax. In: Spatial vision (Regan D, ed), pp 135-178. I ondon: Macmillan.

Regan D, Beverley KI (1978) Looming detectors in the human visual pathway. Vision Res 18:415-421.

Regan D, Beverley KI (1979) Binocular and monocular stimuli for motion-in-depth: changing disparity and changing-size feed the same motion-in-depth stage. Vision Res 19:1331-1342.

Regan D, Beverley KI (1980) Visual responses to changing size and to sideways motion for different directions of motion in depth: linearization of visual responses. J Opt Soc Am 70:1289-1296. 
Regan D, Beverley KI (1983) Spatial frequency detection and discrimination: comparison of postadaption thresholds. J Opt Soc Am 73:1684-1690.

Regan D, Beverley KI (1984) Figure-ground segregation by motion contrast and by luminance contrast. J Opt Soc Am A 1:433-442.

Regan D, Beverley KI (1985) Postadaptation orientation discrimination. J Opt Soc Am A 2:147-155.

Regan D, Cynader M (1979) Neuronx in cat area 18 visual cortex selectively sensitive to changing size: nonlinear interactions between responses to two edges. Vision Res 19:699-711.

Regan D, Hamstra S (1990) Shape and orientation discrimination for motion-defined and contrast-defined objects: temporal integration. Invest Ophthamol Vis Sci [Suppl] 31:2578

Regan D, Hamstra S (1991) Shape discrimination for motion-defined and contrast-defined form: squareness is special. Perception 20:315336.

Regan D, Hamstra S (1992) The effects of presentation duration and dot lifetime on orientation discrimination for motion-defined bars and contrast-defined bars. Vision Res, in press.

Regan D, Hong XH (1990) Visual acuity for optotypes made visible by relative motion. Optom Vision Sci 67:49-55.

Regan D, Maxner C (1986) Orientation-dependent loss of contrast sensitivity for pattern and flicker in multiple sclerosis. Clin Vision Sci 1:1-23.

Regan D, Maxner C (1987) Orientation-selective visual loss in patients with Parkinson's disease. Brain 1 10:239-271.

Regan D, Neima D (1983) Low-contrast letter charts as a test of visual function. Ophthalmology 90:1192-1200.

Regan D, Neima D (1984) Low contrast letter charts in early diabetic retinopathy, ocular hypertension, glaucoma and Parkinson's disease. Br J Ophthalmol 68:885-889.

Regan D, Bartol S, Murray TJ, Beverley KI (1982) Spatial frequency discrimination in normal vision and in patients with multiple sclerosis. Brain 105:735-754

Regan D, Erkelens CJ, Collewijn H (1986) Visual field defects for vergence eye movements and for stereomotion perception. Invest Ophthalmol Vis Sci 27:806-819.

Regan D, Kothe AC, Sharpe JA (1991) Recognition of motion-defined shapes in patients with multiple sclerosis and optic neuritis. Brain 114:1129-1155

Reichardt W (1986) Processing of optical information by the visual system of the fly. Vision Res 26:113-126.

Richards W, Regan D (1973) A stereo field map with implications for disparity processing. Invest Ophthalmol Vis Sci 12:904-909.

Saito H, Yukie M, Tanaka K, Hikosaka K, Fukada Y, Iwai E (1986) Integration of direction signals of image motion in the superior temporal sulcus of the macaque monkey. J Neurosci 6:145-157.

Saltzman CD, Britten KH, Newsome WT (1990) Microstimulation of visual area M'I influences perceived direction of motion. Invest Ophthalmol Vis Sci [Suppl] 31:238.

Santen JPH, Sperling G (1984) Temporal covariance model of human motion perception. J Opt Soc Am A 1:451-473.

Santen JPH, Sperling G (1985) Elaborated Reichardt detectors. J Opt Soc Am A 2:300-321

Schiller PH, Logothetis NK, Charles ER (1990) Functions of the coloropponent and broad-band channels of the visual system. Nature 343 : $68-70$.

Sharpe JA, Morrow MJ (1988) Smooth pursuit disorders: physiological and anatomical considerations. In: Vestibular disorders (Barber AO, Sharpe JA, eds), pp 129-158. Chicago: Year Book Medical.
Sherk H (1986) The claustrum and the cerebral cortex. In: Cerebral cortex, Vol 5 (Jones EG, Peters A, eds), pp 467-499. New York: Plenum.

Siegel RM, Andersen RA (1988) Perception of three-dimensional structure from motion in monkey and man. Nature 331:259-261.

Sokol S, Moskowitz A, Reese D, Brown B (1990) Low contrast letter acuity in childhood amblyopia. Clin Vis Sci 5:243-247.

Switkes E, Bradley A, DeValois KK (1988) Contrast dependence and mechanisms of masking interactions among chromatic and luminance gratings. J Opt Soc Am A 5:1149-1162.

Tanaka K, Saito H-A (1989) Analysis of motion of the visual field by direction, expansion/contraction and rotation cells clustered in the dorsal part of the medial superior temporal area of the macaque monkey. J Neurophysiol 62:626-641.

Tanaka K, Hikosaka K, Saito Y (1986) Analysis of local and widefield movements in the superior temporal visual areas of the macaque monkey. J Neurosci 6:134-144.

Tanaka K, Fukada Y, Saito H-A (1989) Underlying mechanisms of the response specificity of expansion, contraction and rotation cells in the dorsal part of the medial superior temporal area of the macaque monkey. J Neurophysiol 62:642-656.

Teuber H-L (1960) Perception. In: Handbook of physiology, Vol 3, Sec 1, Neurophysiology (Field J, Magoun HW, Hall VE, eds), pp 1595-1669. Baltimore: Williams and Wilkins.

Tigges J, Tigges M (1985) Subcortical sources of direct projections to visual cortex. In: Cerebral cortex, Vol 3 (Peters A, Jones EG, eds), pp 351-378. New York: Plenum Press.

Tyler CW (1991) Cyclopean vision. In: Spatial vision (Regan D, ed), pp 38-74. London: Macmillan.

Ungerleider LG, Mishkin M (1982) Two cortical visual systems. In: Analysis of visual behaviour (Ingle DJ, Goodale MA, Mansfield RJW, eds), pp 549-586. Cambridge, MA: MIT Press.

Vaina LM (1989) Selective impairment of visual motion interpretation following lesions of the right occipito-parietal area in humans. Biol Cybern 61:347-359.

Van Essen DC (1985) Functional organization of primate visual cortex. In: Cerebral cortex (Peters A, Jones EG, eds), vol 3, pp 259-329. New York: Plenum.

Van Essen DC, Maunsell JHR (1983) Hierarchical organization and functional streams in the visual cortex. Trends Neurosci 6:370-375.

Van Essen DC, Felleman DJ, De Yoe EA, Olavarria J, Knierim J (1990) Modular and hierarchical organization of extrastriate visual cortex in the macaque. In: The brain, vol 15, pp 679-696. Cold Spring Harbor, NY: Cold Spring Harbor Laboratory.

von Helmholtz H (1866) Physiological optics, Vol 3. Reprint, 1909, 1924 (Southall JPC, transl). New York: Dover, 1962.

Williams DW, Sekuler R (1984) Coherent global motion percepts from stochastic local motions. Vision Res 24:55-62.

Wilson HR (1991) Psychophysical models of spatial vision and hyperacuity. In: Spatial vision (Regan D, ed), pp 64-86. London: Macmillan.

Zeki SM (1974) Functional organization of visual areas in the posterior bank of the superior temporal sulcus of the rhesus monkey. $J$ Physiol (Lond) 236:549-573.

Zihl J, Von Cramon D, Mai N (1983) Selective disturbance of movement vision after bilateral brain damage. Brain 106:313-340.

Zucker SW (1984) Type I and typc II processes in carly oricntation selection. In: Figural synthesis (Dodwell PC, Caelli T, eds), pp 283300. London: Earlbaum. 